\title{
Biological Markers of Training Level among Qualified Greco-Roman Wrestlers
}

\author{
Khoren Tonoyan ${ }^{1 *}$ (D) Lyubov Tarasova ${ }^{2,3}$ (D) Alexander Korzhenevskiy ${ }^{2}$ (D) \\ ${ }^{1}$ Chair of Physical Education, UNK SP of Moscow University, Ministry of Internal Affairs of Russia named after V.Ya. Kikoty, \\ Moscow, Russia; ${ }^{2}$ Laboratory for Problems of Comlex Support of Sports Training, Federal Science Center for Physical Culture \\ and Sports, Moscow, Russia; ${ }^{3}$ Department of Theory and Methods of Physical Education and Sports, Moscow State Regional \\ University, Mytishchi, Moscow Region, Russia
}

Edited by: Slavica Hristomanova-Mitkovska Citation: Tonoyan K, Tarasova L, Korzhenevskiy A. reco-Roman Wrestlers. Open Access Maced J Med Sci. 2022 Jan 01; 10(A): 12-15 https://doi.org/10.3889/oamims.2022.7505 Keywords: Greco-Roman wrestlers; Markers; Adaptation Training loads; Pre-competition training

Correspondence: Khoren Tonoyan, Chair of Physical Education, UNK SP of Moscow University, Ministry of Internal Affairs of Russia named after V.Ya. Kikoty, Moscow, Russia.
E-mail: professor-tonoyan@mail.ru Received: 29-Sep-2021 Revised: 22-Nov-2021 Accepted: 22-Dec-202 Copyright: $\odot 2022$ Khoren Tonoyan, Lyubov Tarasova
Alexander Korzhenevskiy
Funding: This research did not receive any financia Copyright: $\odot 2022$ Khoren Tonoyan, Lyubov Tarasova
Alexander Korzhenevskiy
Funding: This research did not receive any financia Funding: This research did not receive any financia Competing Interests: The authors have declared that no competing interests exis Open Access: This is an open-access article distributed under the terms of the Creative Commons Attribution-

\begin{abstract}
BACKGROUND: The article presents the dynamics of biochemical indicators showing the tension of body functiona systems in qualified Greco-Roman wrestlers at the pre-competition stage. Biochemical indicators can be regarded as the markers of training level, as a reflection of adaptive changes during performing training loads.

AIM: The study aims to examine the adaptive reactions of body internal systems in wrestlers to the load performed at the stage of pre-competition training.

METHODS: The methodological basis of the study is the examination of the reaction of body functional systems in wrestlers $(n=24)$ in response to the load performed at the stage of pre-competition training. The basis of the studied indicators of wrestlers' organisms is the dynamics of the enzymatic activity (ALT and AST), the activity of creatine phosphokinase, and the balance of anabolic and catabolic processes in the course of a 2-week macrocycle of the pre-competition training.

RESULTS: A high level of enzymatic activity (ALT and AST) was noted as the response to shock training load in the first and the second training macrocycles against the background of a negative trend during the entire sports event, which indicates a directed decrease in the heart's tension muscle, being an indicator of adaptive changes occurring in wrestlers' body energy. The high variability of AST indicators on the first day and creatine phosphokinase throughout the entire pre-competition training pointed out an individual level of adaptive reactions of the athletes' bodies in response to the training load taken.
\end{abstract}

CONCLUSIONS: The results of the study have shown notable dynamics in the indicators of the enzymatic activity of AST, creatine phosphokinase, and the hormone cortisol in a series of shock training loads, as the response to adaptive changes in body energy systems, the value of which should be considered during the pre-competition training.

\section{Introduction}

The conducted study is devoted to the examination and improvement of the pre-competition training of qualified Greco-Roman wrestlers. Being an integral task of managing the training process, it is associated with the development of criteria for assessing technical skills, physical, and functional training level based on the biochemical parameters of blood. In the process of pre-competition training, it seems relevant to develop additional criteria for assessing the surveyed groups of Greco-Roman wrestlers, which makes it possible to judge their condition at a specific time and identify the leading factors that contribute to their achievement of a high functional and physical condition, as well as develop effective programs for their further training. The solution of this problem is essential and especially important for qualified athletes, and does not consist in forced specialized training, but in purposeful training that models competition.
During sports performances, Greco-Roman wrestlers need to show maximum strength, vestibular stability, coordination, and endurance, which are an advantage in an equal fight. Short-term repetitive fights show the advantage of attacking actions in conditions of active dynamic work of a glycolytic nature. The pre-competition stage of the training of Greco-Roman wrestlers is particularly important, while the macrocycles of that stage model competition-like training loads. The goal of the study is to examine the adaptive reactions of the internal systems of Greco-Roman wrestlers' organisms to the load performed during pre-competition training.

The pre-competition shock training of qualified Greco-Roman wrestlers causes a specific manifestation of the functional reactions in their bodies' internal systems.

The analysis of sports training of qualified Greco-Roman wrestlers has shown that there is no unified approach to assessing the adaptive mechanisms 
of body energy systems at the pre-competition stage, which indicates the novelty of this study. Previously, performed works have shown the demand for the study of the control of heart rate variability in strength sports athletes [1], [2], [3], [4]; the control of biochemical parameters of athletes' training level by the example of weightlifters and martial arts athletes [5], [6]; the connection between heart rate and steroid hormones in their impact on muscle load [7], [8]; hormonal activity of testosterone and cortisol, and the effect of cortisol on the psych emotional state of strength sports athletes [8], [9], [10], [11], [12], [13]; control of thyroid-stimulating hormone during physical activity [14], [15]; and complex diagnostics of training level [16], [17], [18], [19], [20], [21].

The quantity of functional shifts in the body of qualified Greco-Roman wrestlers depends on the power of the performed load and the degree of responses. Taking into account the specific nature of training work in Greco-Roman wrestling, one should consider the internal tension of functional systems, the size, and duration of their manifestations as the energy costs of the performed loads. The loads performed in the conditions of pre-competition training form the response of the athletes' organism functional systems, which in the process of competitive wrestling is the criterion for assessing training level. All this indicates the novelty of the study.

\section{Methods}

The control of the studied indicators was executed in the context of the present surveys in the precompetition training period. The study has covered the dynamics of enzymatic activity of ALT and AST and the balance of the hormones cortisol and testosterone, as a reflection of the anabolic and catabolic mechanisms of the body's reaction in the macrocycle of pre-competition training of Greco-Roman wrestlers $(n=24)$.

Biochemical studies were carried out on the $1^{\text {st }}$ training day of the microcycle, the $4^{\text {th }}$ and the $9^{\text {th }}$ shock training days of the microcycle, and the $7^{\text {th }}$ and the $12^{\text {th }}$ off days. The control of the studied indicators was carried out with regard to the present surveys at the stage of a 12-day pre-competition training.

\section{Results}

The prerequisite for this study was the examination of markers of the adaptive changes in Greco-Roman wrestlers' body functional systems at the stage of pre-competition training, which simulated competition.
The reaction of the athletes' bodies to the load performed in the process of pre-competition training is the marker of the adaptive reactions that model a competitive macrocycle. The responsive adaptation mechanism to the performed loads creates the need to take into account additional criteria for functional support in the process of pre-competition training.

The core subjects of the study have been the dynamics of the enzymatic activity of ALT and AST as an indicator of the muscular supply to special strength workout; the cardiovascular system as an indicator of the energy supply of the body; liver function as a mechanism regulating metabolic processes during muscular work; and balance of anabolic and catabolic processes - cortisol/testosterone - in response to the loads performed. The repetition of training loads during pre-competition training is cyclical, which forms the responsive reaction in athletes' bodies when ensuring a high level of training.

The results of the study indicated the responsive nature of the enzymatic activity of AST in response to the loads performed on the $1^{\text {st }}$, the $4^{\text {th }}$, and the $9^{\text {th }}$ load days during the pre-competition training period $(52.3 \pm 24.6 \mathrm{U} / \mathrm{L} ; 56.4 \pm 16.3 \mathrm{U} / \mathrm{L}$; and $57.1 \pm 13.1 \mathrm{U} / \mathrm{L}$, respectively), along with ALT response on the same shock training days being within the physiological norm $(41.9 \pm 22.0 \mathrm{U} / \mathrm{L} ; 37.6 \pm 14.7 \mathrm{U} / \mathrm{L}$; and $38.9 \pm 13.7 \mathrm{U} / \mathrm{L}$, respectively). This indicates the response of the cardiovascular and hepatobiliary systems in conditions of intense muscular work, as the marker of the adaptive reactions of body energy systems in Greco-Roman wrestlers (Figure 1).

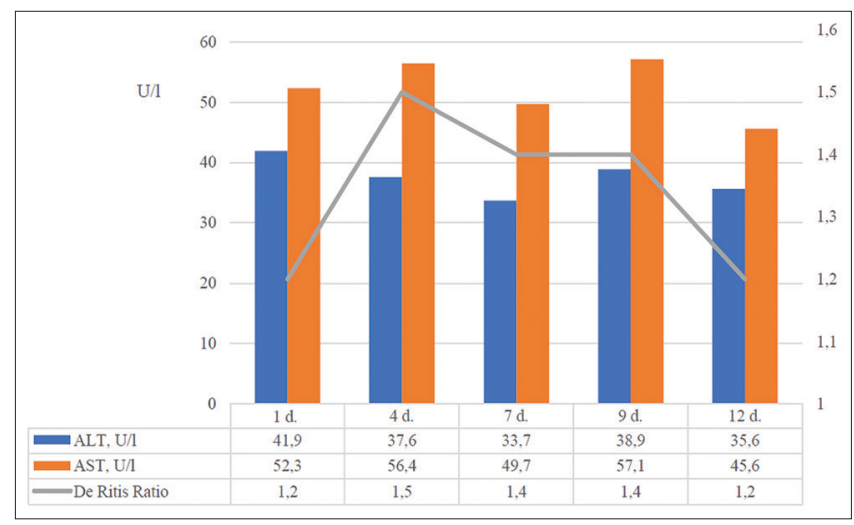

Figure 1: Dynamics of indicators of ALT and in qualified GrecoRoman wrestlers at the stage of pre-competition training

The reaction of AST and ALT indicates the amount of work performed in the pre-competition training by qualified athletes. The variability of AST indicators on the $1^{\text {st }}$ and the $9^{\text {th }}$ days of the pre-competition training points out the individual reactivity of the athletes' organism in response to the competition-like shock training load performed. A decrease in the variability of the studied indicator during the pre-competition training is a phenomenon of the adaptive reaction of GrecoRoman wrestlers' body energy systems. 
It should be noted that De Ritis ratio, reflecting the AST/ALT correlation throughout the entire macrocycle, remains within the normal range $(1.34 \pm 0.1)$, which indicates the optimal reaction of the functioning of the cardiovascular and hepatobiliary systems of the athletes' bodies in the process of pre-competition training.

The balance of anabolic and catabolic hormones (cortisol/testosterone) in the pre-competition training macrocycle remains within the physiological norm, which indicates an adequate responsive reaction of the body to the performed load (Figure 2).

\begin{tabular}{|c|c|c|c|c|c|c|c|}
\hline \multirow{8}{*}{$\mathrm{nmol} / 1$} & 548 & & & & & & 23 \\
\hline & 528 & & & & & & 22,5 \\
\hline & & & & & 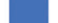 & & 22 \\
\hline & 488 & & & & & & 21,5 \\
\hline & 468 & & & & & & 21 \\
\hline & 448 & & & & & & 20,5 \\
\hline & 428 & & & & & & 20 \\
\hline & 408 & $1 \mathrm{~d}$ & $4 \mathrm{~d}$. & $7 \mathrm{~d}$. & $9 \mathrm{~d}$. & $12 \mathrm{~d}$. & 19,5 \\
\hline Cortisol, $\mathrm{nmol} / 1$ & & 465,1 & 539,3 & 473,3 & 521,3 & 536,2 & \\
\hline -Testosterone, $\mathrm{nmol}$ & & 21,8 & 22,1 & 22,4 & 20,5 & 21,4 & \\
\hline
\end{tabular}

Figure 2: Dynamics of indicators of cortisol and testosterone of qualified Greco-Roman wrestlers at the stage of pre-competition training

Along with this, the dynamics of the stress hormone cortisol reflect the effect of shock training loads within the physiological norm on the $4^{\text {th }}$ and the $9^{\text {th }}$ days $(539.3 \pm 99.0 \mathrm{nmol} / \mathrm{L}$ and $521.3 \pm 111.3 \mathrm{nmol} / \mathrm{L}$, respectively) with a tendency to increase by the start of competition performance, thus being an indicator of neurohumoral reactions of the central nervous system, associated with an increase in psycho-emotional stress. The dynamics of the testosterone hormone balance the effect of shock training loads in relation to catabolic reactions $(22.1 \pm 5.6 \mathrm{nmol} / \mathrm{L}$ and $20.5 \pm 4.5 \mathrm{nmol} / \mathrm{L}$, respectively).

It is also worth paying attention to the safety of the studied values of the enzymatic activity of ALT and AST, and the hormonal activity of cortisol and testosterone on the $7^{\text {th }}$ and $12^{\text {th }}$ days off, which indicates the formation of a stable reaction of the energy supply of the athletes' bodies during the pre-competition training.

\section{Discussion}

The study of the dynamics of the energy systems' functional reactions in qualified Greco-Roman wrestlers in response to the competition-like shock training loads is a new vector of modern biological studies, indicating the formation of adaptive changes at the stage of pre-competitive training. The study of this issue can be based on the control of the indicators of the functioning of main body systems that provide the efficiency of the cardiovascular and hepatobiliary systems under conditions of intense muscular work, as an energy mechanism of the response of enzymatic activity and the hormonal system.

The results of the study reflected marked reactions of the AST and ALT enzymatic activity against the background of the balanced reaction of cortisol and testosterone in response to the competition-like training loads, thus being a responsive reaction of adaptive changes in qualified Greco-Roman wrestlers' body energy systems at the stage of their pre-competitive training. High variability of AST indicators points out an individual response to the training load performed. A decrease in this variability characterizes the adaptive mechanisms of energy systems to the work performed.

The functioning levels of the qualified GrecoRoman wrestlers' various body systems during precompetition training constitute a scientific interest as an additional criterion for assessing their adaptive response to the performed load, and for optimizing the training process.

Maintaining a high level of enzymatic activity and the balance of hormonal activity on days off indicate a high level of energy supply in athletes during pre-competition macrocycles.

\section{Conclusion}

The results of the study have shown the dynamics of the adaptive reactions of the qualified Greco-Roman wrestlers' energy systems in response to the load performed at the stage of pre-competition training. The functioning levels of the qualified GrecoRoman wrestlers' various body systems during precompetition training constitute a scientific interest as an additional criterion for assessing their adaptive response to the performed load, and for optimizing the training process.

Maintaining a high level of enzymatic activity and the balance of hormonal activity on days off indicate a high level of energy supply in athletes during pre-competition macrocycles. The most notable indicators of AST and ALT on the $1^{\text {st }}$ and $9^{\text {th }}$ days of training macrocycle and in response to shock training are the biological markers of the training level of qualified Greco-Roman wrestlers. Another marker is the increasing role of the stress hormone cortisol in response to psycho-emotional stress on the eve of the competition.

The dynamics of variability of AST indicators should be taken into account as biological markers of individual training level at the stage of pre-competition training, being a reaction of body functional systems in response to the loads performed, which forms a 
new look at the study of the adaptive mechanism of the energy systems in Greco-Roman wrestlers. The stability of the mechanisms of energy supply on the days off during the pre-competition macrocycle should be regarded as a high level of adaptation of the GrecoRoman wrestlers' organisms to the loads performed, which indicates the need to take this factor into account in the process of athletes' preparation.

\section{References}

1. Rabbani A, Baseri MK, Reisi J, Clemente FM, Kargarfard M. Monitoring collegiate soccer players during a congested match schedule: Heart rate variability versus subjective wellness measures. Physiol Behav. 2018;194:527-31. https://doi. org/10.1016/j.physbeh.2018.07.001

PMid:29981763

2. Mishchenko IA, Volynskaya EV, Korobova SA. Functional state monitoring in taekwondo athletes by means of heart rate variability in the pre-competition period. Human Sport Med. 2021;21(2):42-50.

3. Tibana RA, de Sousa NM, Prestes J, Feito Y, Ernesto C, Voltarelli FA. Monitoring training load, well-being, heart rate variability, and competitive performance of a functional-fitness female athlete: A case study. Sports. 2019;7(2):35. https://doi. org/10.3390/sports 7020035

PMid:30744103

4. Pokhachevskiy AL, Lapkin MM, Birchenko NS Pokhachevskiy DA, Pozhimalin VN, Gadzhimuradov FR, et al. Prognostic potential of exercise cardiac rhythmogram during period. Human Sport Med. 2018;18(1):46-59. https://doi. org/10.14529/hsm180104

5. Potapov VN, Rybakov VV, Antropova EV. Individualization in the system of training of elite weightlifters based on biochemical criteria of the body state assessment. Human Sport Med. 2017;17(1):87-91. https://doi.org/10.14529/hsm170109

6. Terzi MS, Lekontsev EV, Saraykin DA, Pavlov VI, Kamskova YG. Molecular genetic determination of functional performance of combatants of different skill levels. Theory Pract Phys Cult. 2016;7:21-4.

7. Samikulin PN, Gryaznikh AV, Kuchin RV, Nenenko ND. Changes in heart rate variability in response to muscular load and their correlation with the concentration of steroid hormones in young males with different training specifics. Human Sport Med. 2018;18(1):33-45. https://doi.org/10.14529/hsm180103

8. Souza RA, Beltran OA, Zapata DM, Silva E, Freitas WZ, Junior RV, et al. Heart rate variability, salivary cortisol and competitive state anxiety responses during pre-competition and pre-training moments. Biol Sport. 2019;36(1):39-46. https://doi. org/10.5114/biolsport.2018.78905

PMid:30899138
9. Çınar V, Talaghir LG, Akbulut T, Turgut M, Sarikaya M. The effects of the zinc supplementation and weight trainings on the testosterone levels. Human Sport Med. 2017;17(4):58-63. https://doi.org/10.14529/hsm170407

10. Izov N, Alexandrova A, Petrov L, Kachaunov M, Sheytanova T, Kolimechkov S. Dynamics of training distress, performance, and excretion of cortisol and cortisone in urine during six weeks of training in elite swimmers. Human Sport Med. 2020;20(S1):84-91. https://doi.org/10.14529/hsm20s111

11. Samikulin PN, Gryaznykh AV. Changes of cortisol values in young men with different levels of physical fitness during recovery after submaximal muscular load. Human Sport Med. 2017;17(1):5-13. https://doi.org/10.14529/hsm170101

12. Turbasova NV, Bulygin AS, Revnivykh IY, Karpov NV, Elifanov AV. Anxiety level and parameters of the cardiovascular system in athletes of various qualifications. Human Sport Med. 2019;19(4):14-9. https://doi.org/10.14529/hsm190402

13. Saraykin DA, Bacherikov EL, Kamskova YG, Pavlova VI. Study of physiological indicators of taekwondo athletes in sensory conflict. Theory Pract Phys Cult. 2017;12:62-4.

14. Kornyakova VV, Sautkin YA, Zabolotnykh MV, Konway VD, Stepanova IP, Ashvits IV, et al. Thyroid status during physical exertion. Intern J Appl Fundam Res. 2018;5(1):175-9.

15. Sagliocchi S, Cicatiello AG, Di Cicco E, Ambrosio R, Miro C Di Girolamo D. The thyroid hormone activating enzyme, Type 2 deiodinase, induces myogenic differentiation by regulating mitochondrial metabolism and reducing oxidative stress. Redox Biol. 2019;24:101228. https://doi.org/10.1016/j. redox.2019.101228

PMid:31153038

16. Korzhenevsky AN, Klendar VA, Kurguzov GV, Tarasova LV. The use of complex diagnostics for assessing the fitness of weightlifters. Human Sport Med. 2019;19(S2):45-50.

17. Tarasova LV, Korzhenevsky AN, Tarasov PY. Leading indicators of the training of qualified weightlifters at the stage of precompetitive training. In: Proceedings of the $1^{\text {st }}$ International Volga Conference on Economics, Humanities and Sports (FICEHS 2019). Kazan, Russia: Atlantis Press; 2019. p. 734-5.

18. Agostinho MF, Philippe AG, Marcolino GS, Pereira ER, Busso $\mathrm{T}$, Candau $\mathrm{R}$, et al. Perceived training intensity and performance changes quantification in judo. J Strength Cond Res. 2015;29(6):1570-7. https://doi.org/10.1519/ JSC. 0000000000000777 PMid:25436630

19. Aminov AS, Kokin VY, Leshukov VS, Shakhovskiy AP. Boxer's readiness to a fight in the deficiency of time. Human Sport Med. 2018;18(S):120-4. https://doi.org/10.14529/hsm18s17

20. Manolachi VG, Potop V, Manolachi VV, Dorgan VP. Planning of effort parameters in the training of elite male judo athletes. Hum Sport Med. 2021;21(2):162-73.

21. Saraykin DA, Epishev VV, Pavlova VI, Kamskova YG Dynamical changes in postural balance of vertical position in elite taekwondo practitioners within a full-year macrocycle. Hum Sport Med. 2017;17(3):25-34. https://doi.org/10.14529/ hsm170303 